\title{
DISCRIMINATIVE STIMULUS EFFECTS OF $N$-SUBSTITUTED ANALOGS OF PHENCYCLIDINE IN RHESUS MONKEYS
}

\author{
R. E. SOlomon*, S. Herling, E. F. Domino and J. H. Woods $\dagger$ \\ Departments of Pharmacology and Psychology, University of Michigan, Ann Arbor, \\ MI 48109, U.S.A.
}

(Accepted 5 June 1982)

\begin{abstract}
Summary --In daily sessions of a two-lever, discrete-trial, food-reinforced procedure, rhesus monkeys were trained to discriminate between subcutaneous injections of ketamine $(1.0$ or $1.8 \mathrm{mg} / \mathrm{kg})$ and control injections. In tests of stimulus generalization, cumulative doses of drugs were administered in single sessions and either control- or kelamine-appropriate responding produced food. Ketamine (1.8 and $3.2 \mathrm{mg} / \mathrm{kg})$ and phencyclidine $(0.32 \mathrm{mg} / \mathrm{kg})$ produced an average of more than $90 \%$ ketamine-appropriate responding. In contrast. $d$-amphetamine, atropine, chlorpromazine, codeine, diazepam and quipazine. tested at doses up to and including those that markedly reduced response rates, produced exclusively control-appropriate responding. Dose-related ketamine-appropriate responding was produced by each of ten 1-phenylcyclohexylamines, the potencies of which varied with the length, electronegativity, and number of $N$-alkyl chains present. The most potent analog of phencyclidine, $N$-ethyl-1-phenylcyclohexylamine, was approximately equipotent with phencyclidine. These data are consistent with previous reports that the discriminative stimulus effects produced by phencyclidine are representative of a unique class of drugs, and that alkyl substitutions in the region of the piperidine ring alter the potency, but not the characteristic pharmacological activity, of the resulting analogs. The potencies of some of these analogs compared to phencyclidine in rhesus monkeys, however, differed from their relative potencies in rodents. Thus, there appear to be species differences in the role of the nitrogen pharmacophore of these compounds in producing phencyclidine-like behavioral effects.
\end{abstract}

Developed originally as an anesthetic, phencyclidine (PCP) was found to offer several advantages, such as a lack of cardiovascular and respiratory depression at anesthetic doses in laboratory animals (Chen, 1958) and in man (Chen, Ensor, Russel and Bohner, 1959). Upon emergence from anesthesia, however, phencyclidine was found to produce a dissociative state characterized by feelings of unreality, anxiety and depersonalization (Greifenstein, DeVault, Yoshitake and Gajewski. 1958). Additionally, phencyclidine produces subjective and behavioral effects which more closely resemble the primary symptoms of schizophrenia than do the effects produced by other psychotomimetic agents. such as D-lysergic acid diethylamide (LSD) (Cohen, Rosenbaum, Luby, Gottlieb and Yelen, 1959; Luby, Cohen, Rosenbaum, Gottlieb and Kelley. 1959; Cohen, Rosenbaum, Luby and Gottlieb, 1962). The magnitude of these effects and the frequency with which they occur have prevented phencyclidine from being used for anesthesia in humans. Ketamine is a less potent and shorter-acting analog of phencyclidine (McCarthy, Chen. Kemp and Ensor, 1965) that continues to be used clinically, although it is not en-

* Present address: University of Iowa, College of Medicine, Iowa City. IA 52242, U.S.A.

† To whom correspondence should be addressed.

Key words: drug discrimination, cumulative dose-effects, rhesus monkeys, ketamine. phencyclidine, 1-phenylcyclohexylamines. tirely free of dissociative activity (Domino, Chodoff and Corssen, 1965). Despite its presumably unpleasant effects, phencyclidine has emerged as a drug of widespread abuse (Peterson and Stillman, 1978), and ketamine as well as several other analogs of phencyclidine have been identified in illicit samples, suggesting that they may share abuse liability with phencyclidine (Shulgin and MacLean, 1976).

Similarities between the discriminative stimulus effects of phencyclidine and ketamine have been demonstrated in a number of species, including rats (Overton, 1975; Jãrbe, Johannson and Henriksson, 1975; Poling, White and Appel, 1979; Holtzman, 1980; Shannon, 1981), pigeons (Herling, Coale, Hein, Winger and Woods, 1981) and squirrel monkeys (Brady and Balster, 1981). A variety of structural analogs of phencyclidine also share discriminative effects with the parent compound (Shannon, 1981; Brady and Balster, 1981), while a number of psychoactive drugs from various pharmacological classes (e.g. LSD, $d$-amphetamine, pentobarbital and tetrahydrocannabinol) do not (Poling et al., 1979; Shannon, 1981). These data suggest that phencyclidine and its analogs act through common neuropharmacological mechanisms that are distinct from those of other psychoactive drugs. Evidence for biologically significant receptor sites for phencyclidine has recently been provided by reports of the displacement of $\left[{ }^{3} \mathrm{H}\right]$ phencyclidine from rat and pigeon brain membranes by appropriate concentrations of drugs which produce behavioral 
effects resembling those of phencyclidine (Vincent, Kartalovski, Geneste, Kamenka and Lazdunski, 1979; Zukin and Zukin. 1979, 1981: Hampton, Medzihradsky and Woods, 1980, 1982).

The present experiment was designed, firstly, to demonstrate that phencyclidine and ketamine share discriminative stimulus effects in another species, the rhesus monkey. Because the behavioral effects of phencyclidine in man more closely resemble its effects in nonhuman primates than in rodents or avian species (Chen, 1958), the actions of phencyclidine and related drugs in the rhesus monkey may be more closely related to their pharmacology in man. Secondly, the pharmacological specificity of the discriminative effects of ketamine was investigated by evaluating a number of psychoactive agents for the ability to engender responding appropriate for ketamine. Finally, a series of structural analogs of phencyclidine was evaluated for the ability to produce ketamine-like discriminative effects. The analogs of phencyclidine tested in this experiment contained various $N$-alkyl substitutions in place of the piperidine ring of phencyclidine and thus provided a basis for systematically evaluating structure-activity relationships at the nitrogen pharmacophore. In rodents, alkyl substitutions in this part of the molecule alter the potency but not the pharmacological activity of analogs of phencyclidine (Jasinski, Shannon, Cone. Vaupel, Risner, McQuinn, Su and Pickworth, 1981; Shannon, 1981; Shannon and DeGregorio, 1981). In the present experiment, the generalization of this finding to the rhesus monkey was investigated

\section{METHODS}

\section{Subjects}

Three rhesus monkeys (Macaca mulatta) were trained to lever press with food reinforcement (Ferster and Skinner. 1957) and were maintained at weights of $7.0-9.0 \mathrm{~kg}$, which represented approx. $80^{\circ}{ }_{\circ}$ of their free-feeding weights. Each monkey was housed individually and was given sufficient food (Purina High Protein Monkey Chow, No. 5045, Ralston-Purina Co.n St Louis, MO) following the daily experimental sessions to maintain these reduced weights. Water was freely available in the home cages and fresh fruit was provided several times a week. Isoniazid $(40 \mathrm{mg})$ was administered daily on a sugar cube.

Each monkey (754, 794 and 808) had a complex experimental and drug history; however none of the monkeys had received drug discrimination training prior to this experiment. For each animal, at least 6 months intervened between previous experiments and the beginning of this study.

\section{Apparatus}

Each experimental chamber was equipped with two response levers (model PRL-001/121-07, BRS-LVE,
Beltsville, MD) mounted about $10 \mathrm{~cm}$ apart and equidistant from a food receptacle. The levers and food receptacle were mounted approx. $50 \mathrm{~cm}$ above the floor of the chamber and were within easy reach of the monkey. The chamber was ventilated by an exhaust fan. and a loudspeaker mounted inside the chamber provided continuous white masking noise. An array of colored 7-W bulbs (model C7-CC. General Electric Co.. St Louis, MO) was mounted at the top of the front wall inside the chamber. Bananaflavored food pellets $(300 \mathrm{mg}$. Formula G, P. J. Noyes Co., Lancaster, $\mathrm{NH}$ ) were delivered to the food receptacle by a pellet dispenser (Model A. Ralph Gerbrands ('o., Arlington. MA) mounted outside the chamber. Programming. recording and data collection were accomplished with a computer (Model 960A. Texas Instruments Co.. Dallas, TX) and cumulative recorders (Model C-3. Ralph Gerbrands Co.).

\section{Training procedure}

The procedure has been described previously (Bertalmio, Herling, Hampton, Winger and Woods, 1982). Before each daily session, each monkey was removed from its home cage and placed in a primate restraining chair. Monkey and chair were then placed in the experimental chamber and the monkey was given either a subcutaneous injection of $1.8 \mathrm{mg} / \mathrm{kg}$ of ketamine or a control injection. After a 10 min blackout two blue lights inside the chamber were illuminated and each press of the lever designated as correct for the session resulted in the delivery of a food pellet. The designation of "correctness" depended on the injection given prior to the session; e.g. the right lever after ketamine and the left lever after control. Training sessions were conducted 6 days per week with ketamine and control injections alternating daily.

The response requirement was increased throughout the sessions to 100 consecutive responses. When a monkey emitted a minimum of $90^{\prime \prime}{ }^{\prime}$ correct responses for five consecutive sessions, the final phase of training was initiated. Daily sessions consisted of a series of $5 \mathrm{~min}$ trials separated by $10 \mathrm{~min}$ blackout periods. Immediately before each blackout period, the monkey was given either a control injection or a subcutaneous injection of $1.8 \mathrm{mg} / \mathrm{kg}$ of ketamine. After $10 \mathrm{~min}$. the trial began and completion of 100 consecutive responses on the correct lever resulted in the delivery of $3 \mathrm{~g}$ of food. Responses on the incorrect lever reset the response requirement on the correct level to 100 . At the end of $5 \mathrm{~min}$, whether food had been delivered or not, the trial ended and the monkey received the next injection, $10 \mathrm{~min}$ prior to the start of the next trial. Thus, the time between successive injections was constant (i.e. $15 \mathrm{~min}$ ), irrespective of the rate of responding in a particular trial.

Each training session began with from zero to four control trials and ended with two drug trials. The number of control trials was varied from day to day to prevent the detection of the drug trials on the basis 
of the number of preceding control trials. All control trials were preceded by control injections, but only the first of the two drug trials was preceded by an injection of ketamine. The second drug trial was preceded by a control injection. since ketamine was assumed to be present from the first drug trial. A discrimination was considered to be established when a monkey emitted a minimum of $90^{\circ} ;$ correct responses in each trial for five consecutive sessions. During this phase of discrimination training. it was necessary to decrease the training dose of ketamine to $1.0 \mathrm{mg} / \mathrm{kg}$ for one monkey (808), as this animal consistently did not complete the response requirement following the injection of $1.8 \mathrm{mg} / \mathrm{kg}$ of ketamine. The smaller training dose in this monkey and the original training dose in the other two monkeys were maintained throughout the remainder of the experiment.

\section{Testing procedure}

Test sessions were identical to training sessions, except that in each trial 100 consecutive responses on the lever appropriate for either control injections or ketamine injections resulted in the delivery of food, and each trial was preceded by a subcutaneous injection of the test drug which increased the total dose injected within the session by $1 / 4$ or $1 / 2 \log$-unit steps. In general, a test session continued until the monkey made at least $90 \%$ of its responses in two successive trials on the lever appropriate for ketamine or until responding in two successive trials was markedly suppressed. If food reinforcement was not obtained in a trial at a given dose of a test compound (i.e. if the monkey did not emit 100 consecutive responses on either the control- or ketamine-appropriate lever), the following trial was preceded by a control injection, and the data from both trials were averaged in analyzing the effects of that dose of the test compound.

Training and test sessions were conducted in alternation 6 days per week. If a monkey failed to exhibit criterion performance in a training session (i.e. at least $90 \%$ correct responses in each trial), testing sessions were not conducted until criterion performance was attained in two consecutive training sessions.

\section{Data analyses}

The data on the discriminative control of hehavior exerted by each dose of the test compounds were calculated as the mean percentage of ketamine-appropriate responses \pm 1 SEM. If the rate of lever-press responding by an individual monkey at a dose of a test compound was less than 0.1 responses/sec, the percentage of ketamine-appropriate responses emitted by that monkey at that dose was not included in the calculations. For each compound which produced dose-related ketamine-appropriate responding, the smallest dose tested that produced maximum ketamine-appropriate responding was calculated as a mean \pm 1 SEM. Potencies compared to phencyclidine were obtained by dividing the mean dose of phencyclidine $(\mu \mathrm{mol} / \mathrm{kg})$ which produced maximum ketamine- appropriate responding by the mean dose of each compound ( $\mu \mathrm{mol} / \mathrm{kg}$ ) which produced the same effect. At each dose of all compounds tested, the rates at which responses were emitted, irrespective of the lever on which they occurred, were calculated in responses/ sec.

\section{Drugs}

The drugs used in this experiment were ketamine hydrochloride (Warner-Lambert, Ann Arbor, MI), phencyclidine hydrochloride, 1-phenylcyclohexylamine hydrochloride. $N$-methyl-, $N$-ethyl-, $N$-propyl-, $\quad N$-butyl-, $\quad N$-isopropyl-, $\quad N$-sec-butyl-, $\quad N, N$ dimethyl-, and N,N-diethyl-1-phenylcyclohexylamine hydrochloride (provided by Dr Robert E. Willette, National Institute on Drug Abuse, Bethesda, MD). $N$-allyl-1-phenylcyclohexylamine hydrochloride (provided by Dr Asher Kalir. Israel Institute of Biological Research, Ness-Ziona, Israel), d-amphetamine sulfate (Sigma Chemical Co., St Louis. MO), atropine sulfate (Ruger Chemical Co., Irvington, NJ). chlorpromazine hydrochloride (Sinith Kline \& French Laboratories, Philadelphia, PA), codeine phosphate (S.B. Penick \& Co., Lyndhurst, NJ), diazepam (base) (Hoffmann-La Roche, Inc., Nutley, NJ) and quipazine maleate (Miles Laboratories, Elkhart, IN). Diazepam was dissolved in a solution containing $40^{\circ}$ propylene glycol, $10^{\circ}$ 。 ethanol, $5 \%$ sodium benzoate and benzoic acid. $1.5^{\circ}$ o benzyl alcohol and $43.5^{\circ}$; sterile water. The remainder of the drugs were dissolved in sterile $0.9^{\circ}{ }_{0}$ sodium chloride. Doses are expressed as the forms described above.

\section{RESULTS}

Discriminations were established with ketamine in each monkey. The number of training sessions required until criterion performance was attained in each animal was 48,51 and 52. In training sessions, the rate of lever-press responding in trials that were preceded by control injections ranged between 2.0 and 4.0 responses $/ \mathrm{sec}$. Response rates decreased to between 0.1 and 2.5 responses/sec in the first of the two trials that followed injections of ketamine. In the second of these trials, response rates approximated those which followed control injections. Throughout the course of these experiments, which were conducted over approximately 1 ycar, there was no apparent development of tolerance to the response rate-decreasing effects of ketamine. In addition, each animal consistently performed at or above criterion levels during the training sessions that were interposed between dose-response determinations of test compounds. Occasional substitution of saline injections for control injections, as well as tests with saline, produced only control-appropriate responding.

In tests of stimulus generalization, the smallest dose of ketamine $(0.1 \mathrm{mg} / \mathrm{kg})$ produced only control-appropriate responding (Fig. 1, upper left panel). Increasing 


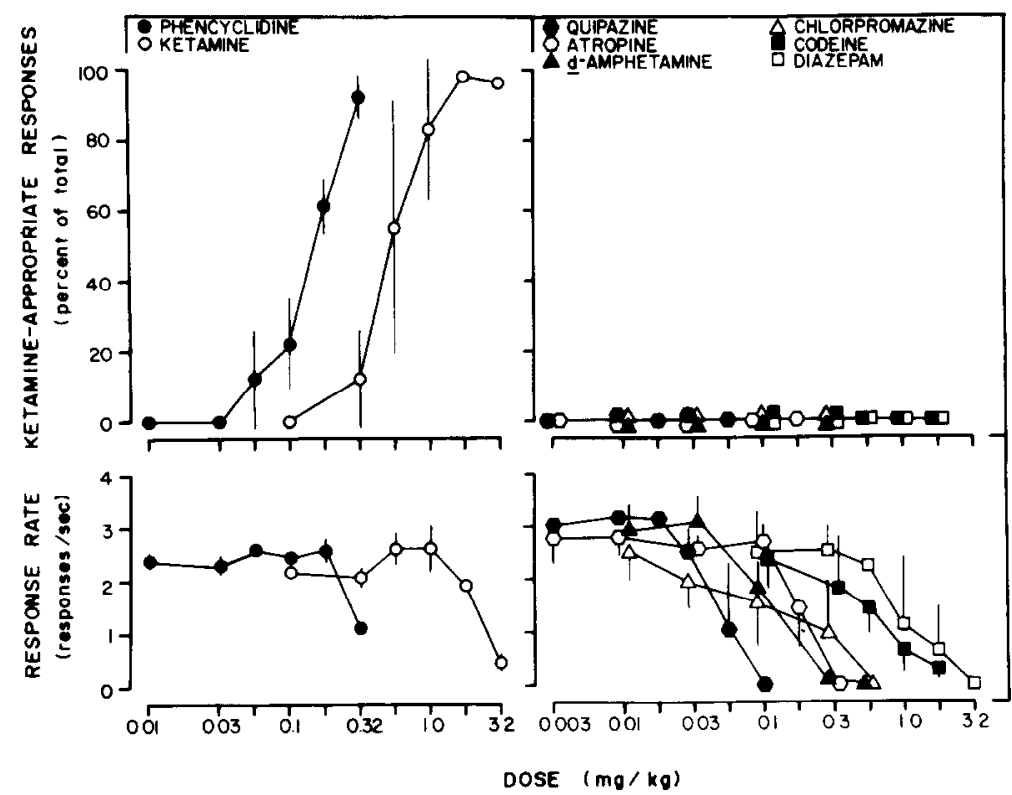

Fig. 1. Cumulative dose-response curves of the discriminative control of behavior exerted by phencyclidine and ketamine (upper left panel) and by six drugs that failed to produce stimulus control of behavior similar to that of ketamine (upper right panel) in rhesus monkeys trained to discriminate subcutaneous injections of ketamine from control injections, and the effects of these drugs on the rate of lever-press responding (lower panels). The upper panel ordinates indicate the average number of responses emitted on the ketamine-appropriate lever, expressed as a percentage of the total trial responses. The lower panel ordinates indicate the average rate of responding after injection of drug expressed in responses/sec. The abscissae indicate the cumulative doses of the drugs. in milligrams per kilogram. Vertical lines through the points indicate \pm 1 SEM.

cumulative doses of ketamine produced a dose-related increase in the percentage of total responses emitted on the ketamine-appropriate lever that reached $90^{\circ}$ \% or greater in each of the monkeys at 1.8 and $3.2 \mathrm{mg} / \mathrm{kg}$ (Fig. 1. upper left panel). Phencyclidine also produced dose-related ketamine-appropriate responding which was greater than $90^{\circ}{ }_{0}$ at $0.32 \mathrm{mg} / \mathrm{kg}$ (Fig. 1 , upper left panel). Thus, phencyclidine was approxi- mately six-times more potent than ketamine. Both ketamine and phencyclidine produced decreases in the rate of lever-press responding at doses that produced $90 \%$ or greater ketamine-appropriate responding (Fig. 1, lower left panel). Larger doses of both drugs eliminated responding, and ataxia, excessive salivation and nystagmus were noted in each monkey at these doses. In contrast to ketamine and phencyc-

Table 1. Chemical structures of $N$-substituted analogs of phencyclidine

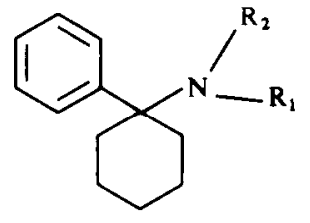

\begin{tabular}{|c|c|c|c|}
\hline & Compound & $\mathrm{R} 1$ & $\mathrm{R} 2$ \\
\hline I. & PCA (1-Phenylcyclohexylamine) & $\mathbf{H}$ & $\mathbf{H}$ \\
\hline II. & NMPCA ( $N$-Methyl-1-phenylcyclohexylamine) & $\mathrm{CH}_{3}$ & $\mathbf{H}$ \\
\hline III. & NEPCA (N-Ethyl-1-phenylcyclohexylamine) & $\mathrm{CH}_{2} \mathrm{CH}_{3}$ & $\mathrm{H}$ \\
\hline IV. & NPPCA ( $N$-Propyl-1-phenylcyclohexylamine) & $\mathrm{CH}_{2} \mathrm{CH}_{2} \mathrm{CH}_{3}$ & $\mathrm{H}$ \\
\hline V. & NBPCA (N-Butyl-1-phenylcyclohexylamine) & $\mathrm{CH}_{2} \mathrm{CH}_{2} \mathrm{CH}_{2} \mathrm{CH}_{3}$ & $\mathrm{H}$ \\
\hline VI. & NAPCA ( $N$-Allyl-1-phenylcyclohexylamine) & $\mathrm{CH}_{2} \mathrm{CH}=\mathrm{CH}_{2}$ & $\mathrm{H}$ \\
\hline VII. & NIPCA ( $N$-Isopropyl-1-phenylcyclohexylamine) & $\mathrm{CH}\left(\mathrm{CH}_{3}\right)_{2}$ & $\mathrm{H}$ \\
\hline VIII. & NSPCA ( $N$-sec-Butyl-1-phenylcyclohexylamine) & $\mathrm{CH}_{2} \mathrm{CH}\left(\mathrm{CH}_{3}\right)_{2}$ & $\mathrm{H}$ \\
\hline IX. & PCDMA ( $N, N$-Dimethyl-1-phenylcyclohexylamine) & $\mathrm{CH}_{3}$ & $\mathrm{CH}_{3}$ \\
\hline $\mathbf{X}$. & PCDEA ( $N, N$-Diethyl-1-phenylcyclohexylamine) & $\mathrm{CH}_{2} \mathrm{CH}_{3}$ & $\mathrm{CH}_{2} \mathrm{CH}_{3}$ \\
\hline
\end{tabular}


Table 2. Results of tests with phencyclidine (PCP) and $N$-substitued analogs of phencyclidine

\begin{tabular}{|c|c|c|c|c|c|}
\hline & Compound & $\begin{array}{c}\text { Dose range } \\
\text { tested } \\
(\mathrm{mg} / \mathrm{kg})\end{array}$ & $\begin{array}{l}\text { Maximum } \\
\text { ketamine- } \\
\text { appropriate } \\
\text { responding* }\end{array}$ & Doset & Response rate + \\
\hline & PCP & $0.01-0.32$ & $91.7 \pm 6.5$ & $0.32 \pm 0.00$ & $1.08 \pm 0.14$ \\
\hline I. & PCA & $0.10-5.6$ & $93.0 \pm 7.0$ & $4.33 \pm 1.55$ & $1.52 \perp 0.83$ \\
\hline II. & NMPCA & $0.10-3.2$ & $76.7 \pm 23.3$ & $1.53 \pm 0.33$ & $1.86 \pm 0.56$ \\
\hline III. & NEPCA & $0.01-0.56$ & $77.3 \pm 17.7$ & $0.27 \pm 0.06$ & $2.29 \pm 0.25$ \\
\hline IV. & NPPCA & $0.01 \cdot 1.0$ & $80.7 \pm 12.4$ & $0.50 \pm 0.12$ & $1.71 \pm 0.52$ \\
\hline v. & NBPCA & $0.10-1.8$ & $96.3 \pm 2.3$ & $0.87 \pm 0.16$ & $3.14 \pm 0.21$ \\
\hline VI. & NAPCA & $0.01-1.8$ & $96.0 \pm 4.0$ & $1.03 \pm 0.53$ & $2.38 \pm 0.43$ \\
\hline VII. & NIPCA & $0.01-0.6$ & $75.0 \pm 17.7$ & $0.30 \mp 0.00$ & $1.40 \pm 0.61$ \\
\hline VIIII. & NSPCA & $0.10-1.0$ & $90.3 \pm 6.0$ & $0.60 \pm 0.00$ & $1.43 \pm 0.77$ \\
\hline IX. & PCDMA & $0.10-5.6$ & $62.7 \pm 34.8$ & $2.00 \pm 0.78$ & $1.58 \pm 0.29$ \\
\hline $\mathbf{X}$. & PCDEA & $0.01-1.8$ & $94.3 \pm 5.7$ & $0.71 \pm 0.18$ & $2.02 \pm 1.06$ \\
\hline
\end{tabular}

* Percentage of total $( \pm 1$ SEM) based on the average of dose-effect curves determined in three monkeys.

+ Average cumulative dose $(\mathrm{mg} / \mathrm{kg} \pm 1$ SEM) that produced maximum ketamineappropriate responding.

$¥$ Average rate of responding (responses $/$ sec \pm 1 SEM) at doses that produced maximum ketamine-appropriate responding.

lidine, quipazine, atropine, $d$-amphetamine, chlorpromazine, codeine and diazepam produced exclusively control-appropriate responding in each monkey at all doses tested (Fig. 1. upper right panel). which included doses that markedly reduced response rates (Fig. 1, lower right panel).

Each of the $N$-substituted analogs of phencyclidine tested in this experiment (Table 1) produced effects that were similar to the effects produced by ketamine and phencyclidine. The dose range of each compound that was tested is shown in Table 2. Following the smallest dose of each analog, responding occurred exclusively on the control-appropriate lever. As the dose of each compound was increased, there was a concomitant increase in the percentage of total responses that were emitted on the ketamine-appropriate lever. The average maximum ketamine-appropriate responding produced by each analog varied from 62.7 to $96.3^{\circ} \%$ (Table 2 ). However, each of the analogs produced greater than $75^{\circ}$ o ketamine-appropriate responding at one or more doses in at least two of the monkeys. In the instances where the average maximum amount of ketamine-appropriate responding was less than $90^{\circ}$ o (e.g. compound IX, PCDMA; Table 2), the large standard errors reflect the fact that two monkeys responded almost cxclusively on the ketamine-appropriate lever at one or more doses, while the third did not. The average rates of responding at the doses of each analog that produced maximum ketamine-appropriate responding are shown in Table 2. At the largest dose of each analog, response rates were decreased considerably, and ataxia, excessive salivation and nystagmus were observed. There was an approx. 20-fold difference in potency between the least potent (i.e. compound I, PCA) and the most potent (i.e. compound III. NEPCA; Table 2) of the $N$-substituted analogs of phencyclidine. The $N$-ethyl analog (NEPCA) produced maximum ketamineappropriate responding at a mean dose of $0.27 \mathrm{mg} / \mathrm{kg}$ (Table 2) and was thus slightly more potent than phencyclidine. On a $\mu \mathrm{mol} / \mathrm{kg}$ basis. however. this compound was approximately equipotent with phencyclidine (Table 3 ).

Compounds $\mathbf{I}-\mathbf{V}$ form an homologous series of $\mathrm{N}$-substituted analogs of phencyclidine with increasing length of the single, saturated, unbranched, $N$-alkyl chain. I he most potent compound in this series was $N$-ethyl-1-phenylcyclohexylamine (Table 2. compound III. NEPCA). There was an orderly decrease in potency as the $N$-alkyl chain was increased or decreased from two carbons in length (Table 2).

The only analog of phencyclidine that contained an unsaturated $N$-alkyl chain (compound VI, NAPCA) was approximately one-half as potent as its saturated counterpart (compound IV, NPPCA; Table 2). Both of the analogs which contained branched $N$-alkyl chains (compounds VII and VIII) were somewhat more potent than their respective straight-chain isomers (compounds IV and $\mathbf{V}$; Table 2). Finally, two $N . N$-dialkyl analogs (compounds $\mathbf{I X}$ and $\mathbf{X}$ ) were somewhat less potent than their respective monoalkyl counterparts (compounds II and III: Table 2). The $N, N$-diethyl analog (compound $\mathbf{X}$, PCDE $\Lambda$ ), which differs from phencyclidine only by the lack of a single methylene group between the two $\mathrm{N}$-alkyl chains, was about one-half as potent as phencyclidine.

\section{DISCUSSION}

Rhesus monkeys trained to discriminate ketamine from control injections generalized completely to phencyclidine, which was approximately six-times more potent than ketamine in producing dose-rclated 
Table 3. Potencies of $N$-substituted analogs of phencychdine compared to phencyclidine using different assays

\begin{tabular}{|c|c|c|c|c|c|c|}
\hline & Compound & $\begin{array}{c}\text { (A) } \\
\text { Rhesus } \\
\text { monkey } \\
\text { discriminative } \\
\text { stimulus }\end{array}$ & $\begin{array}{l}\text { discri } \\
\text { stim }\end{array}$ & $\begin{array}{l}\text { ative } \\
s^{* \dagger}\end{array}$ & $\begin{array}{c}(C) \\
\text { Mouse } \\
\text { rotarod* }\end{array}$ & $\begin{array}{l}\text { (D) } \\
\text { Displacement of } \\
{\left[{ }^{3} \mathrm{H}\right] \mathrm{PCP} \text { from }} \\
\text { rat brain } \\
\text { membranes* }\end{array}$ \\
\hline & PCP & $1.00 \div$ & & & 1.00 & 1.00 \\
\hline III. & NEPCA & 1.02 & & & 1.84 & 0.13 \\
\hline VIII. & NIPCA & 0.97 & & & NTS & 0.23 \\
\hline IV. & NPPCA & 0.58 & & & 0.74 & 0.19 \\
\hline VIII. & NSPCA & 0.51 & & & 0.28 & 0.46 \\
\hline $\mathbf{X}$ & PCDEA & 0.43 & & & 0.37 & 0.22 \\
\hline$V$ & NBPCA & 0.35 & & & 0.37 & 0.08 \\
\hline$V I$. & NAPCA & 0.28 & & & NT & NT \\
\hline II. & NMPCA & 0.17 & & & 0.82 & 0.15 \\
\hline IX. & PCDMA & 0.14 & & & NT & 0.15 \\
\hline I. & PCA & 0.06 & & & 0.22 & 0.01 \\
\hline \multicolumn{7}{|c|}{ Cocfficients of correlation } \\
\hline \multicolumn{7}{|c|}{$\begin{array}{c}\text { Cocfficients of correlation } \\
r\end{array}$} \\
\hline & & $A$ is $B$ & 0.70 & 8 & $<0.025$ & \\
\hline & & A vs $C$ & 0.75 & 6 & $<0.025$ & \\
\hline & & A vs D & 0.53 & 8 & NS & \\
\hline & & $B$ vi $C$ & 0.91 & 6 & $<0.0025$ & \\
\hline & & B vs D & -0.08 & 8 & NS & \\
\hline & & $C$ is $D$ & 0.14 & 6 & NS & \\
\hline
\end{tabular}

* Jasinski et al. (1981). In: Phencrclidine (PCP): Current and Historical Perspectives (Domino, E. F.. Ed.), pp. 331-400. Ann Arbor, NPP Books.

† Shannon (1981) J. Pharmac, exp. Ther. 216: 543-551.

$\ddagger \mu \mathrm{mol}$ of PCP equivalent to $1 \mu \mathrm{mol}$ of listed compound.

$\$$ Not tested.

${ }_{1}$ One-tailed test for significant deviation from the normal distribution (null hypothcsis: $r=0$ ).

ketamine-appropriate responding. These results are consistent with numerous previous reports of the discriminative stimulus effects of these drugs in other species (e.g. Holtzman. 1980; Shannon, 1981; Herling et al., 1981; Brady and Balster, 1981). The subjective syndrome produced by phencyclidine, which includes disorientation. drunkenness, and psychotomimetic effects (e.g. Luby et al., 1959), is also produced by ketamine (Domino et ul., 1965). Thus, the results of this experiment are consistent with the supposition that drug generalization studies are appropriate for assessing similarities in the subjective effects produced by drugs in man (e.g. Holtzman, Shannon and Schaefer. 1977).

In contrast to ketamine and phencyclidine only control-appropriate responding was produced by $d$-amphetamine, atropine, chlorpromazine, codeine, diazepam and quipazine, although each drug was tested at doses up to and including those which were behaviorally active. The pharmacological specificity of the discriminative stimulus effects of ketamine and phencyclidine in rhesus monkeys is in general agreement with previous reports of the specificity of phencyclidine-like discriminative stimuli in other species, in that barbiturates, cannabinols, hallucinogens, certain narcotics and agonists or antagonists of dopaminergic, serotonergic or cholinergic systems do not substitutc for phencyclidinc (Järbe et al., 1975;
Overton, 1975; Poling et al., 1979; Shannon, 1981). Thus, data from this and previous experiments indicate that the discriminative stimulus effects produced by phencyclidine are representative of a unique class of drugs.

The $N$-substituted analogs of phencyclidine tested in the present experiment were similar to phencyclidine in that each produced dose-related ketamineappropriate responding. Thus, there do not appear to be strict structural requirements in the region of the piperidine moiety of phencyclidine for producing phencyclidine-like behavioral effects in rhesus monkeys. These results are consistent with previously reported data on the phencyclidine-like discriminative stimulus effects of many of these analogs in rats (Shannon, 1981).

In contrast to the qualitative similarity between the effects produced by phencyclidine and a number of its $N$-substituted analogs, there were large differences in the doses at which these compounds produced ketamine-appropriate responding. In the absence of extensive pharmacodynamic or pharmacokinetic data on a series of $N$-substituted analogs of phencyclidine, the variations in potency which resulted from small structural differences among these compounds suggest certain characteristics of the putative phencyclidine receptor (Vincent et al., 1979; Zukin and Zukin. 1979). The $N$-ethyl analog was the most potent among an 
homologous series of primary amines and potency decreased in an orderly fashion as the length of the $N$-substituted alkyl chain was altered by substituting either different primary $N$-alkyl groups or $N$-alkyl groups that contained a secondary carbon. These results suggest that the putative phencyclidine receptor may contain a site which interacts most readily with a two-carbon hydrophobic substituent at the nitrogen atom of these compounds. In addition, the decrease in potency observed upon replacing the saturated $N$-alkyl chain of one of these analogs (NPPCA) by its unsaturated counterpart (NAPCA) further implies that this region of the putative phencyclidine receptor may be relatively lipophilic in character. Finally, the greater potency of phencyclidine compared to its $N, N$-diethyl analog (PCDEA) suggests that the planar. rigid piperidine moiety confers a greater affinity for the receptor than do similar, nonrigid, $N$-alkyl substititutions. Thus, the area of the phencyclidine receptor site with which the nitrogen pharmacophore interacts appears to be relatively flat.

The phencyclidine-like behavioral effects of several $\mathrm{N}$-substituted analogs in rodents and their potencies in displacing $\left[{ }^{3} \mathrm{H}\right]$ phencyclidine from membranes of rat brain were studied by Jasinski et al. (1981). The potencies of these compounds compared to phencyclidine are shown in Table 3 , as are their relative potencies as determined in the present experiment. Only the relative potencies of these compounds in producing behavioral effects are significantly correlated. While the order of potencies within certain subgroups of these analogs were often similar in rhesus monkeys and in rodents (e.g. NEPCA was the most potent analog in each of the behavioral assays), certain analogs were more potent than phencyclidine in rodents. whereas none of the compounds was more potent than phencyclidine in rhesus monkeys. Similarly, NFPCA has been found to be two- to six-times more potent than phencyclidine in disrupting forced motor performance in mice (Kalir, Edery. Pelah. Balderman and Porath. 1969; Kalir, Mayanii, Rehavi, Elkavets, Pri-Bar, Buchman and Sokolovsky, 1978; Balster, 1980) and in affecting avoidance responding in rats (Shannon and DeGregorio, 1981), whereas in monkeys this compound is less potent than phencyclidine in producing catelepsy (Chen, 1965), characteristic changes in the spontaneous EEG (Gehrmann and Killam. 1979), effects on fixed-interval performance (Brady, Balster, Meltzer and Schwertz, 1980) and phencyclidine-like discriminative effects (Brady and Balster, 1981). Thus, despite the significant correlations between the relative potencies of these compounds in producing behavioral effects in rodent and primate species, there is considerable evidence for species differences in structure-activity relationships at the nitrogen pharmacophore of phencyclidine.

These results may be due to species differences in the distribution or biotransformation of these compounds. For example, NEPCA has been found to enter the brain to a greater extent than phencyclidine following systemic administration in mice (Kalir et al.. 1978). For the lack of comparable data in primates, however, the suggestion that this finding may account for the greater potency of NEPCA compared to phencyclidine in rodents in comparison to the relative potencies of these two compounds in primates (Brady and Balster, 1981) remains only a possibility. On the other hand. there may be differences between rodents and primates in the physiochemical characteristics of the putative phencyclidine receptor site. Further data are necessary to determine which of these mechanisms might account for the observed species differences.

It is interesting to note that the relative potencies of phencyclidine and its $N$-substituted analogs in producing behavioral effects in rhesus monkeys or in rodents were not well correlated with their relative potencies in displacing $\left[{ }^{3} \mathrm{H}\right]$ phencyclidine from membranes of rat brain (Table 3). Differences between the relative intrinsic affinities and intrinsic activities of these compounds may account for these results (see Jasinski et al., 1981 for discussion). However, the procedure used to measure the displacement of membrane-bound $\left[{ }^{3} \mathrm{H}\right]$ phencyclidine by Jasinski et al. (1981) has been shown to be confounded by the displacement of phencyclidine from glass fiber filters (Maayani and Weinstein, 1980). It has recently been shown that the interference with displaceable binding of $\left[{ }^{3} \mathrm{H}\right]$ phencyclidine by glass filters is markedly reduced by pre-soaking the filters in polyethyleneimine (Hampton et al., 1980, 1982) or polylysine (Zukin and Zukin, 1981). Displaceable binding of $\left[{ }^{3} \mathrm{H}\right]$ phencyclidine to membranes of rat and pigeon brain, studied with this method, exhibits stereoselectivity (Hampton et al., 1980, 1982) consistent with that demonstrated for producing discriminative stimuli similar to those of phencyclidine and ketamine in pigeons (unpublished observations). Comparable binding data on a series of $N$-substituted analogs of phencyclidine. however. have not yet been reported.

In conclusion. the present data support the hypothesis that substitution of various $N$-alkyl groups for the piperidine moiety of phencyclidine alters the potency, but not the characteristic pharmacological activity, of the resulting compounds (Jasinski et al.. 1981). Thus. the suggestion that certain of these analogs may be abused for their phencyclidine-like effects (Shulgin and MacLean, 1976) is supported by the present findings, and implies that strict control of phencyclidine alone is not likely to prevent the abuse of phencyclidine. Additionally, the structure-activity relationships observed between $N$-substituted analogs of phencyclidine in rhesus monkeys suggest the presence of a flat, lipophilic area at the active site of the putative phencyclidine receptor with which the nitrogen pharmacophore of these compounds may interact. Finally, the present data provide further evidence for differences between rodents and primates in structure-activity relationships between phencyclidine and its $N$-substituted analogs. 
Acknowledgements - This research was supported by USPHS grants DA-00154 and DA-01531, and represents a portion of a Psychology Honors thesis of R.E.S. A preliminary report of these data appears in The Pharmacologist 23: 151 (1981). The authors wish to thank Dr Jonathan L. Katz for making helpful suggestions on an earlier version of the manuscript, and Denise Gakle and Kate Johnson for secretarial assistance.

\section{REFERENCES}

Balster, R. L. (1980). The effects of phencyclidine and three analogues on motor performance in mice. Pharmacology 20: $46-51$.

Bertalmio, A. J., Herling, S., Hampton. R. Y., Winger, G and Woods J. H. (1982). A procedure for rapid evaluation of the discriminative stimulus effects of drugs. $J$. Pharmac, Meth. 7: 289-299.

Brady, K. T. and Balster, R. L. (1981). Discriminative stimulus properties of phencyclidine and five analogues in the squirrel monkey. Pharmac. Biochem. Behat. 14: 213-218.

Brady, K. T., Balster, R. L., Meltzer, L. T. and Schwertz, D. (1980). Comparison of phencyclidine and three analogues on fixed interval performance in rhesus monkeys. Pharmac, Biochem. Behat. 12: 67-71.

Chen, G. (1958). Pharmacology of 1-(1-phenylcyclohexyl) piperidine HCl. Fedn Proc. Fedn Am. Socs exp. Biol. 17: 357 (Abstr.)

Chen, G. (1965). Evaluation of phencyclidine-like cataleptic activity. Archs int. Pharmacodyn. Ther. 157: 193-201.

Chen. G., Ensor. C. R.. Russel, D. and Bohner, B. (1959). The pharmacology of 1-(1-phenylcyclohexyl) piperidine HCl. J. Pharmac. exp. Ther. 127: 241-250.

Cohen, B. D., Rosenbaum, G., Luby, E. D. and Gottlieb, J. S. (1962). Comparison of phencyclidine hydrochloride (Sernyl) with other drugs. II. Symbolic and sequential thinking. Archs gen. Psychiat. 6: 395-401.

Cohen, B. D., Rosenbaum, G.. Luby, E. D., Gottlieb, J. S. and Yelen, D. (1959). Comparison of Sernyl with other drugs. I. Attention, motor function, and proprioception. Archs gen. Psychiat. 1: 651-656.

Domino, E. F., Chodoff. P. and Corssen, G. (1965), Pharmacologic effects of CI-581, a new dissociative anesthetic, in man. Clin. Pharmac. Ther. 6: 279 291.

Ferster, C. B. and Skinner, B. F. (1957). Schedules of Reinforcement. Appleton-Century-Crofts. New York.

Gehrmann, J. E. and Killam, K. F. (1979). Activity of phencyclidine and nine of its congeners on the spontaneous EEG in Macaca mulatta. Fedn Proc. Fedn Am. Socs exp. Biol. 38: 436 (Abstr.).

Greifenstein, F. E., DeVault, M.. Yoshitake. J, and Gajewski, J. E. (1958). A study of a 1-arylcyclohexylamine for anesthesia. Anesth. Analg. Curr. Re's. 37: 283-294.

Hampton. R. Y., Medzihradsky, F, and Woods, J. H (1980). Stereospecific binding of phencyclidine in brain membranes. Pharmacologist 22: 285.

Hampton, R. Y., Medzihradsky, F. and Woods, J. H (1982). Stereospecific binding of phencyclidine in brain mcmbranes. Life Sci. 30: 2147-2154.

Herling. S. Coale. E. H.. Jr. Hein. D. W., Winger. G. and Woods, J. H. (1981). Similarity of the discriminative stimulus effects of ketamine, cyclazocine, and dextrorphan in the pigeon. Psychopharmacologl 73: 286291 .

Holtzman, S. G. (1980). Phencyclidine-like discriminative effects of opioids in the rat. J. Pharmac. exp. Ther. 214: 614.619.

Holtzman. S. G., Shannon. H. E. and Schaefer, G. J. (1977). Discriminative properties of narcotic antagonists. In: Discriminative Stimulus Propertie's of Drags (H. Lal, Ed.). pp. 47-72. Plenum, New York.

Järbe. T. U. C., Johansson, J. O. and Henriksson, B. G. (1975). Drug discrimination in rats: The effects of phencyclidine and ditran. Psichopharmacologia 42: 33--39.

Jasinski. D. R., Shannon. H. E., Cone. E. J., Vaupel, D. B., Risner, M. E.. McQuinn, R. L.. Su, T.-P. and Pickworth, W. B. (1981). Interdisciplinary studies on phencyclidine. In: Phencyclidine (PCP): Current and Historical Perspectices (Domino, E. F.. Ed.), pp. 331 400. Ann Arbor. NPP Books.

Kalir, A.. Edery, H., Pelah. Z., Balderman. D. and Porath. G. (1969). 1-Phenylcyclohexylalkylamine derivatives II. Synthesis and pharmacological activity. J. med. Ch'm. 12: $473-477$.

Kalir. A.. Maayanı. S., Rehavi. M.. Elkavets. R.. Pri-Bar. I., Buchman, O. and Sokolovsky, M. (1978). Structure-activity relationships of some phencyclidine derivatives: In (ivo studies in mice. Eur. J. med. Chem. 13: 17-24.

Luby, E. D.. Cohen, B. D., Rosenbaum. G., Gottlieb, J. S. and Kelley, R. (1959). Study of a new schizophrenomimetic drug-Sernyl. Archs Neurol. Psichiat. 81: 363369.

Maayani. S. and Weinstein. H. (1980). "Specific binding" of $\left[{ }^{3} \mathrm{H}\right]$ phencyclidine: Artifacts of the rapid filtration method. Life Sci. 26: 2011 - 2022.

McCarthy. D. A. Chen, G.. Kemp. D. H. and Ensor. C. (1965). General anesthetic and other pharmacological properties of 2-(0-chlorophenyl)-2-methylamino cyclohexanone $\mathrm{HCl} . J$. New Drugs. 5: $21-33$.

Overton, D. A. (1975). A comparison of the discriminable CNS effects of ketamine, phencyclidine, and pentobarbital. Archs int. Pharmacodyn Ther. 215: 180-184.

Peterson, .R. C. and Stillman, R. C. (1978). Phoncyclidinc (PCP) Abuse: An Appraisul. NIDA Research Monograph 21. U.S. Govt. Printing Office. Washington. D.C.

Poling, A. D.. White, F. J. and Appel, J. B. (1979). Discriminative stımulus propertes of phencyclidine. Neturepharmacology 18: 459463.

Shannon. H. E. (1981). Evaluation of phencyclidine analogs on the basis of their discriminative stimulus properties in the rat. J. Pharmac exp. Ther. 216: 543551.

Shannon. H. E. and DeGregorio, C. M. (1981). Effects of $N$-substituted analogs and metabolites of phencyclidine on avoidance behavior in the rat. $J$. Pharmac. exp. Ther. 218: $55 \quad 62$

Shulgin, A. T. and MacLcan, D. (1976). Illicit synthosis of phencyclidine (PCP) and several of its analogues. Clin. Toxic: 9: 553-560.

Vincent. J. P.. Kartalovski. B. Geneste. P.. Kamenka. J. M. and Lazdunski. M. (1979). Interaction of phencyclidıne ("angel dust") with a specific receptor in rat brain membranes. Proc, natn. Acad. Sci. Li.S.4. 76: 46784682

Zukin, S. R. and Zukin, R. S. (1979). Specific $\left[{ }^{3} \mathrm{H}\right]$-phencyclidine binding in rat central nervous system. Proc. natn. Acad. Sci. L.S.A. 76: 5372-5376.

Zukin. R. S. and Zukin. S. R. (1981). Demonstration of $\left[{ }^{3} \mathrm{H}\right]$-cyclazocine binding to multiple opiate receptor sites. Molec. Pharmac. 20: 246254. 